\title{
LOS ZOMBIES Y LA MALDICIÓN DE LAS PALABRAS EN EL LIBRO DE LAS ILUSIONES DE PAUL AUSTER
}

CÉSAR MARTÍNEZ CALLEJO

Universidad de León

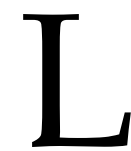

a cita de Chateaubriand con la que se abre el libro es muy reveladora: “El hombre no tiene una sola y única vida, sino muchas, enlazadas unas con otras, y ésa es la causa de su desgracia." La primera parte de esta reflexión no admite muchas dudas, pero la lectura de la novela sí hace plantearse la segunda parte, es decir la desgracia como consecuencia de esas vidas cruzadas. El desarrollo de los acontecimientos que se proyecta en la obra deriva de la creencia, al menos por parte de los personajes, en un determinismo, en un azar consciente que organiza y dispone todos los hechos, sobre todo los luctuosos. Las "coincidencias" se ponen de manifiesto constantemente tanto externa, en boca de los personajes que se ven superados y sorprendidos por ellas, como intratextualmente, de modo que el propio lector se siente abocado a realizar diversas conexiones entre sucesos que aparentemente no guardan relación entre sí. David Zimmer ha perdido en un accidente aéreo a su mujer y a sus dos hijos. Entonces se replantea la secuencia de los hechos, hasta los más insignificantes, que han permitido esa inconmensurable desgracia: su trabajo de profesor que le obligaba a quedarse en Vermont a principios de junio, mientras que su mujer, Helen, debía viajar a Milwaukee para ver a su padre recién operado de un tumor en una pierna; la autorización para faltar las dos últimas semanas que la directora del colegio de Todd a duras penas les concedió. Detalles que lo atormentaban después del accidente y que lo llevan a reflexionar:

Todo formaba parte de lo mismo, cada eslabón de la cadena de la causa y efecto era un elemento fundamental del horror: desde el cáncer que mi suegro tenía en la pierna, pasando por el tiempo que hacía en el Medio Oeste aquella semana, hasta el número de teléfono de la agencia de viajes donde habíamos reservado los billetes. ${ }^{1}$

Desde ese punto de vista, nada es casual, las coincidencias no existen, el azar es, como para los surrealistas, una manifestación de una divinidad todopoderosa que de forma misteriosa o mágica dispone los acontecimientos de

\footnotetext{
${ }^{1}$ El libro de las ilusiones, Barcelona, Anagrama, 2003, p. 15. Todas las citas del libro harán referencia a esta traducción española de Benito Gómez Ibáñez.
} 
nuestra vida de acuerdo a un orden que no suele coincidir con el que nosotros habríamos elegido. Pero la idea de una divinidad o fatum que organiza nuestros destinos es un persistente tópico clásico que suele aparecer vinculado a la noción de la inconsistencia o veleidad de las cosas o estados de la vida, representada tradicionalmente por la Rueda de la Fortuna. De hecho, David Zimmer consigue paradójicamente una inmensa compensación económica por la muerte de su familia "acabé ganando el premio gordo al perdedor" 2 , lo que posibilitará que pueda dejar de trabajar en la universidad y se dedique exclusivamente a escribir un libro sobre el segundo gran protagonista de la obra: Hector Mann quien, a propósito de las ironías del destino, también reconoce: "Dios me ha gastado muchas bromas" 3 . Pero la amarga sonrisa que provocan estas burlas no es sino la triste resignación del hombre ante los incomprensibles designios trazados por esa divinidad caprichosa y voluble.

En efecto, las desmesuradas tragedias dictaminadas de antemano por el fatum los convierten a ambos en héroes del mundo moderno que, a diferencia de los clásicos, se ven desbordados por las desgracias hasta el punto de que sobre sus cabezas pende siempre la idea del suicidio y sólo las apariciones providenciales en sus vidas de Frieda Spelling o de Alma los rescatan de un final prematuro. Es más, ambos estaban "muertos" cuando ellas surgen en sus vidas. Son auténticos zombies que deambulan por un mundo donde casi todo les importa un bledo. Precisamente, cuando Zimmer habla con el médico (que más parece la voz de una sensata conciencia) para que le recete pastillas para dormir durante los vuelos que se ve obligado a realizar, éste le advierte sobre los efectos de la droga Xanax: "Siga las instrucciones de uso, señor Zimmer, y se convertirá en un zombi, en un ser sin personalidad, en un pedazo de carne sin conciencia." 4 Porque tal vez el cabal facultativo no se resigna a creer que Zimmer ya estaba muerto cuando entró en su consulta ("...cuando Helen murió a los treinta y seis años, Todd a los siete y Marco a los cuatro, prácticamente él también había muerto con ellos"5). No se trata simplemente de una frase hecha ya que poco después Zimmer describe su vida cotidiana como un rutinario estado vegetativo en el que su identidad se ha disgregado o reducido sustancialmente: “No sabía quién era, ni tampoco lo que quería, y hasta que encontrara la manera de volver a vivir con los demás, sólo seguiría siendo medio humano"6. De ese estado sale momentánea y exclusivamente para escribir sobre Hector Mann. Es el libro quien lo rescata, es decir la palabra sagrada del arte. Volveré sobre este aspecto más adelante.

Algo muy similar le ocurre a su doble, Hector Mann. Hace sesenta años que había desaparecido de la vida pública por lo que "todo mundo creía que estaba muerto"7 y, como reitera más adelante David Zimmer: "los muertos no andan por ahí saliendo de la tumba, y en mi opinión, sólo un muerto podría

\footnotetext{
2 op. cit., p. 25.

${ }^{3}$ op. cit., p. 241.

4 Op. cit., p. 35.

5 op cit., p. 14.

${ }^{6}$ Op. cit., p. 65.

${ }^{7}$ Es la frase inicial del libro.
} 
haberse mantenido oculto tanto tiempo"8. Del mismo modo Brigid O'Fallon, la amante despechada, también se siente muerta cuando la abandona Hector Mann:

Estaba dispuesta a pasar allí [en un pabellón psiquiátrico] el resto de su existencia, pero sólo porque ahora su único propósito en la vida era encontrar la forma de suicidarse, y daba igual el sitio donde la pusieran ${ }^{9}$

Es más, a todos los protagonistas les ronda la idea del suicidio varias veces a lo largo de la obra ${ }^{10}$. Aquí el concepto del abandono imprime realismo, devuelve los héroes clásicos al mundo moderno. El suicidio del héroe es propio de nuestro mundo y a veces el hado deja que los personajes crean sustraerse a sus dictámenes a través de esa única puerta final.

Pero lo cierto es que la presencia de la muerte trágica o no natural es muy abundante en toda la obra, ya que aquí Tanatos es la ejecutora de los designios del Fatum: Helen y los niños se estrellaron en el avión, Seymor Hunt (el productor de Mann) se ahorcó, a Brigid O'Fallon la mata accidentalmente ("eso es lo que dijo") Dolores Saint John, quien a su vez estrelló su vehículo pocos años después contra un árbol y murió desangrada (una sangre derramada que recuerda la que observa Hector Mann de Brigid O'Fallon ${ }^{11}$ ), Frieda Spelling expiró al golpearse en la cabeza como resultado de un empujón de Alma quien, desesperada por lo que había hecho involuntariamente, se suicida con pastillas. Y, por si fuera poco, sobre la única muerte natural que aparece en el libro, que es la de Hector Mann, pende la sospecha final de que tal vez fue asesinado por su mujer.

En definitiva, todo lo que aman estos héroes es destruido (sus mujeres, sus hijos, sus amantes). Es como si el destino aniquilara cualquier brizna que se interpusiera en el camino trazado previamente por él. Los héroes deben estar solos o momentáneamente acompañados tan solo por aquellos seres que tienen una función más trascendente que la meramente sexual o la familiar. Frieda debe destruir la obra conjunta y después muere, y Zimmer que es el último de ellos que permanece vivo debe contarlo todo en un libro que sólo se publicará una vez que también él haya muerto. Todos son destruidos por Tanatos una vez que cumplen con el plan predeterminado.

Por tanto, los que quedan son zombies porque son seres sin futuro, no pueden ni deben hacer planes a largo plazo, viven a medias, sin entusiasmo, como mucho están enajenados por una obsesión, aquella que creen que les redimirá de ese infierno y los traerá de nuevo a la vida completa. David Zimmer lo reconoce al verse obligado a recorrer con Alma el mismo camino que había hecho con Helen y sus hijos justo antes de morir:

\footnotetext{
8 Ibíd., p. 11.

${ }^{9}$ Ibíd, p. 149.

${ }^{10}$ David Zimmer reconoce: "más de una vez me contuve en medio de prolongadas fantasías sobre pastillas para dormir y gases de monóxido de carbono" (ibíd., p. 17); de Hector Mann se dice al final del libro que "había estado a punto de suicidarse en Montana, Chicago y Cleveland" (ibíd., p. 302) y Alma consigue su nefasto propósito.

11 "Su cuerpo no se había enfriado, y le seguía saliendo sangre de la nuca" (ibíd., p. 152)
} 
Daba la impresión de que era una especie de castigo astutamente ideado, como si los dioses hubieran decidido que no se me permitiría tener futuro hasta que hubiera vuelto al pasado. ${ }^{12}$

Por tanto, son seres que luchan por redimir su culpa porque la forma de volver a la vida es cumpliendo una penitencia apropiada. Algunas de esas redenciones parecen castigos bíblicos o mitológicos: así intuimos que Nora O'Fallon es condenada a casarse con una persona a la que no ama y a pasarse la existencia recordando a Herman Loesser ${ }^{13}$; Alma deberá invertir gran parte de su vida escribiendo un libro que luego verá impotente cómo lo destruye Frieda; Zimmer está condenado a la soledad y al dolor de perder a todos los seres que ama. Y ¿qué decir de Hector Mann? Él se considera culpable de la muerte de Brigid $\mathrm{O}^{\prime}$ Fallon, por lo que decide imponerse su propio castigo:

De todas las torturas que Hector era capaz de imaginar, de todos los dolores que podía infligirse a sí mismo, ninguno era peor que la idea de ir a la ciudad donde vivía esa familia. si llegaba a ver al señor O'Fallon y a las dos chicas, sabría cómo eran, y entonces, cada vez que pensara en el daño que les había causado, sus rostros acudirían a su mente. Se merecía ese padecimiento, pensó. ${ }^{14}$

Así comienza una nueva vida, de las muchas que se entrecruzan en su existencia. Pero, mientras paga esa deuda al destino su karma se complica aún más porque debe renunciar a casarse con la hermana de Brigid, Nora O'Fallon y se ve obligado a huir de nuevo. Pasa por dos intentos de suicidio pero es rescatado por Sylvia Meers, quien lo inicia en otra vida-muerte tortuosa. Cuando recibe el disparo en el pecho está cumpliendo su castigo, aunque todos lo consideren un héroe y cuando muere su hijo también lo acaba aceptando como una ley kármica a cuyo cumplimiento debe resignarse para lavar su culpa de aquel infortunado asesinato ${ }^{15}$ y toda su obra posterior sigue siendo una redención. Por ejemplo, planta árboles que constituirán su única obra póstuma, su único acto creativo perdurable:

Seguía haciendo penitencia, ¿comprendes? Pero ya no intentaba destruirse. Incluso ahora, habla de esos árboles como si fueran su obra más importante. Más que sus películas, dice, más que cualquier cosa que haya hecho en la vida. ${ }^{16}$

De ahí que haga algo tan incomprensible para el resto de los mortales como realizar películas para ser destruidas, a sabiendas de que el público jamás llegará a verlas:

\footnotetext{
${ }^{12}$ Ibíd., p. 129.

13 "Le había conocido hacía mucho tiempo, explicó, pero nunca había podido dejar de pensar en él. Pensaba en él todos los días desde hacía cincuenta y cuatro años" (ibíd., p. 235.)

${ }^{14}$ Ibíd., p. 162. Y un poco más adelante lo reitera: "Ahora él tenía que pagar por ello en los barrios bajos de Spokane..." (p. 179).

${ }^{15}$ Cuando muere el hijo que tiene con Frieda (no se puede olvidar que Brigid O'Fallon estaba embarazada de Hector Mann cuando es asesinada) lo siente "como una especie de castigo divino" (ibíd., p. 222)

${ }^{16}$ Ibíd., p. 220.
} 
Las películas, entonces, eran una especie de penitencia, el reconocimiento de que su participación en el asesinato accidental de Brigid O'Fallon era un pecado que jamás alcanzaría el perdón. [...] Una forma de castigo había sucedido a otra, y en la retorcida lógica de aquella decisión que le servía de tormento, Hector había continuado pagando sus deudas a un Dios en el que se negaba a creer. ${ }^{17}$

Porque Hector interpretaba que dentro de esa penitencia había también una interdicción bíblica: "Prohibido dejar la menor huella tras de sí"18. El reverso de la creación es la destrucción: Eros y Tanatos. Frieda debía convertirse en el brazo ejecutor que borrara su paso por este mundo.

Ciertamente, en todas estas penitencias siempre encaja como mediadora de los designios del hado, una mujer, una intermediaria: Frieda, Alma, pero también Sylvia Meers, Brigid y Nora O'Fallon, entre otras. El Eros que aquí aparece es activo y vengador que puede conceder placeres pero que siempre son efímeros. Es un Eros que se confunde con Tanatos. Así, en la película de Martin Frost, las relaciones sexuales se muestran como algo natural que une pasional e impúdicamente a los personajes del filme, pero que constituyen un arma arrojadiza contra una sociedad esclavizada por las normas del decoro. Bajo este mismo ámbito del impudor aparece el Eros más sexual y menos romántico cuando Hector, después de tocar fondo de nuevo, decide junto con Sylvia Meers dedicarse a la exhibición pública del acto sexual. Una acendrada crítica a la sociedad norteamericana encorsetada en el más rancio reaccionarismo religioso. Él mismo sin embargo, reconoce no tener alma en aquellos instantes. Se ha convertido en un zombie del sexo, en un íncubo de su propio cuerpo. Es la antítesis del Hector Mann elegante que también se exhibe, pero como un pulcro galán, en sus películas de cine mudo. Tal vez este aprendizaje o camino iniciático le da el bagaje necesario para no reprimir las escenas sexuales en sus siguientes películas como un arte ajeno a la represión social. Del mismo modo, la pasión sexual que sienten Zimmer y Alma es una unión carnal en la que Hector, su doble, recupera el "alma" que había perdido junto a Sylvia Meers.

Finalmente pues, todos los acontecimientos que sufren los protagonistas son muertes y redenciones que los reincorporan a "otra" vida diferente de la que habían estado llevando. Y, como ya antes constatamos, en ese interregno entre una y otra se sienten zombies, muertos vivientes:

Una serie de accidentes me había robado la vida para luego devolvérmela, y en ese intervalo, en el minúsculo vacío entre esos dos momentos, mi vida se había convertido en otra vida diferente. ${ }^{19}$

Al final del libro David Zimmer reconoce ese parpadeo de sus diferentes vidas y muertes porque le atribuye a Alma (la intermediaria) el papel de haberlo rescatado del mundo de los muertos: "En ocho días escasos, me había

\footnotetext{
17 Ibíd., p. 295.

18 Ibíd.

19 Ibíd., pp. 123-124.
} 
traído de entre los muertos" 20 . Cada nueva vida de Hector Mann o de su envés David Zimmer, es una nueva reencarnación, el inicio de un nuevo ciclo con su correspondiente karma.

Pero el proceso de redención o reinserción en una nueva vida pasa por un inevitable descensum ad inferos que lleva aparejado también un cambio del espacio físico y en ocasiones una modificación del nombre como parte visible de su nueva identidad. Ya vimos cómo para estos seres el tiempo deja de tener interés porque no tienen futuro y viven el presente como una condena, pero el espacio parece ser determinante a la hora de iniciar una nueva existencia. Así, Hector Mann cambia de lugar de residencia cada vez que inicia una nueva vida (Spokane, Sandusky, Nuevo México); y Zimmer se encierra en un pequeño infierno para traducir a Chateaubriand en Vermont porque el libro sobre Hector Mann era, según sus palabras, Nueva York ${ }^{21}$. Sin embargo no elige un lugar cómodo o que se asemeje a un hogar, sino todo lo contrario:

Era un hospital para muertos vivientes, parada obligada de afligidos, y habitar en aquel interior anodino e impersonal equivalía a comprender que el mundo era una ilusión que había que reinventar cada día. ${ }^{22}$

También Hector Mann se recluye en Nuevo México, en un rancho al que bautiza "Piedra Azul" para recordar así una experiencia muy significativa que había tenido en Sandusky y que había recogido en su diario ${ }^{23}$. Y nombra su finca así porque "Hector ya había visto esa piedra, y sabía que no existía, que la vida que iban a crear para ellos se basaba en una ilusión" 24 . Asunto esencial en el libro a juzgar por el título. La vida como un mundo de sombras o como un sueño. Platón y Calderón de la Barca son sólo algunos de los más famosos intérpretes de esta idea. Paul Auster añade a su novela este juego de espejos en que se debate la existencia de sus personajes, la metáfora del cine como una realidad también soñada, tal vez porque el arte no deja de imitar a la naturaleza ¿o era al revés?:

Hasta que empezó a proyectarse la película en la pantalla frente a mis ojos, todas esas cosas habían sido reales. Ahora, en las imágenes en blanco y negro salidas de la cámara de Charlie Grund, se habían convertido en elementos de un mundo de ficción. Yo debía interpretarlas como sombras, pero mi cerebro no se ajustó con la suficiente rapidez. Una y otra vez, las veía como eran, no como lo que pretendía ser. ${ }^{25}$

Todo es ilusión y todos somos zombies en un mundo de apariencias. Hector Mann, junto con su productor y los periodistas había especulado

\footnotetext{
20 Op. cit., p. 333.

${ }^{21}$ Ibíd., p. 65.

22 Ibíd., p. 66.

${ }^{23}$ Caminando cierto día a través de una niebla que confería un halo fantasmagórico a toda la realidad circundante, logró vislumbrar en el suelo una piedra azul (un ópalo o un zafiro, pensó) pero cuando se disponía a cogerla, ésta se deshizo entre sus manos porque se trataba en realidad de un "escupitajo humano", ibíd., pp. 303-305.

${ }^{24}$ Ibíd., p. 305.

${ }^{25}$ Ibíd., p. 260.
} 
diversas hipótesis sobre su origen, como si de un héroe de novela de caballerías se tratara. Al ir a Sandusky, Hector Mann hace coincidir su existencia real con una imagen creada inopinadamente por un periodista. Vidas fabuladas y vidas reales se confunden intencionada y quijotescamente. $\mathrm{Y}$ como esa imagen grotesca de un escupitajo que se deshace entre los dedos cuando quieren aprehenderlo, también las sucesivas vidas de cada uno de los personajes se diluyen, se difuminan, se pierden en el olvido: la vida de Zimmer como profesor de universidad y padre de familia, su vida como compañero de Alma (sólo permanece su vida como testigo de las vidas de los demás). Tampoco, por supuesto, las vidas de Hector Mann son menos perecederas o inconsistentes: su vida como actor de cine mudo, su vida como padre de familia tanto con Brigid como con Frieda, su vida de exhibicionista pornográfico, su vida como marido ejemplar de Nora O'Fallon, su vida como director de cine sonoro. ¿Qué queda de sus/nuestras vidas entonces? Jorge Manrique también se lo preguntaba, pero dejó inmortalmente plasmada la fugacidad y la inconsistencia de nuestras existencias al preguntarse con el tópico del ubi sunt por los tocados de las damas, por sus vestidos y olores, por la música que escuchaban. Paul Auster también revitaliza aquí ese tópico y su atención incide asimismo en aquellos detalles que en su día nos parecieron mínimos y que tras la desaparición de sus portadores quedan para siempre fijados en nuestro recuerdo ${ }^{26}$. Así ocurre con el único contacto físico que tiene David Zimmer con Hector Mann cuando éste lo coge del brazo se convierte en la prueba fehaciente de que "esto es de verdad"27; o cuando el mismo Zimmer trata absurdamente de cuantificar los actos efímeros de la vida cotidiana:

\footnotetext{
¿Cuánto tiempo había dedicado a atarme los zapatos en mis cuarenta años? ¿Cuántas puertas había abierto y cerrado? ¿Cuántas veces había estornudado? ¿Cuántas horas había perdido buscando objetos que no encontraba? ¿Cuántas veces me había dado con la cabeza o con la punta del pie contra algo o había parpadeado para quitarme una mota que se me había metido en el ojo? 28
}

Pero la expresión de la insustancialidad o fugacidad de la existencia a través de mínimos acontecimientos efímeros culmina en dos momentos: uno, cuando la cámara se detiene en estos detalles que así se convierten en pura poesía cinematográfica en la película La vida interior de Martin Frost:

\footnotetext{
26 Hay un pasaje del libro de Chateaubriand que impresiona a Zimmer en el que aquél narra cómo reconoció la cabeza de María Antonieta en la exhumación 26 años después de su muerte por el recuerdo de su sonrisa, op. cit., p. 78

${ }^{27}$ Ibíd., pp. 242-243.

${ }^{28}$ Ibíd., p. 107. Un cómputo parecido lo llevará a cabo más adelante cuando Alma ya está muerta: "Eso sólo dejaba veintinueve horas en que tuve realmente ocasión de verla y tocarla, de encerrarme en el círculo de su presencia. Hicimos el amor cinco veces. [...] Comimos juntos seis veces. Dos coches, un avión, seis copas de tequila. Tres casas, tres camas en tres noches diferentes. Cuatro conversaciones telefónicas" Incluso llega a una terrible conclusión: "Alma había aparecido en mi vida para desaparecer tan rápidamente que a veces tenía la impresión de habérmela inventado" (Ibíd., p. 332)
} 
...un cacharro con agua hirviendo, una voluta de humo de tabaco, unos visillos blancos flotando frente al resquicio de la ventana entreabierta. Vapor, humo y aire: un catálogo de cosas sin forma ni sustancia. ${ }^{29}$

Y el segundo, cuando David penetra en el cuarto de baño de Alma y enumera como si de un santuario se tratara:

El cepillo de dientes rojo en su soporte de encima del lavabo, las barras de labios en sus estuches dorados o de plástico, el cepillito del rimel y el lápiz de ojos, la caja de tampones, las aspirinas, el hilo dental, el eau de cologne de Chanel n. ${ }^{\circ}$ 5, el bactericida hecho receta. Cada uno de ellos era un signo de intimidad, una marca de soledad e introspección. Alma se llevaba las pastillas a la boca, se aplicaba las cremas en la piel, se pasaba los peines y cepillos por el pelo, y todas la mañanas entraba en aquel cuarto y se ponía frente al mismo espejo en que yo miraba ahora. ${ }^{30}$

Con todo, los que no fuimos testigos de aquellas vidas sólo podemos fiarnos de las palabras de quienes nos lo cuentan. Las palabras son lo único que permanece de aquéllos y de sus ilusorias existencias. Y de lo que fueron sus identidades sólo nos quedan sus nombres: Hector Mann, Herman Loesser, Hector Spelling... así como los juegos fonéticos y semánticos provocados por ellos como un guiño del destino a los personajes o un gesto cómplice para con el lector ${ }^{31}$.

Todo se reduce a palabras: las películas se oralizan ${ }^{32}$, los libros se cuentan, las biografías se narran. Palabras, palabras. No se puede dudar de las palabras. Los personajes nos dan su palabra. Frieda promete destruir las películas y lo cumple, Alma jura no publicar el libro hasta después de la muete de Hector y lo cumple, Hector promete decir la verdad a Alma, y lo cumple. Debemos fiarnos de su palabra. La palabra tiene aquí un valor sagrado. Así, Alma se sorprende de la simultaneidad de dos hechos: cuando Frieda Spelling escribe tres palabras: Querido profesor Zimmer, Hector cae por las escaleras y se

\footnotetext{
${ }^{29}$ Ibíd., p. 272.

${ }^{30}$ Ibíd., p. 298.

${ }^{31}$ El anagrama creado por Mann en Don Nadie con C. Lester Chase y explicado (p. 49), así como el que nos aclara el mismo Mann cuando toma la identidad de Herman Loesser (Herr Mann) (p. 157); o la casi coincidencia para señalar la unicidad de ambos protagonistas entre los nombres de sus hijos muertos: Tad y Todd (p. 222). Anagrama es también, este para el lector, el creado con los apellidos de los dos protagonistas Zimmer Mann o, hablando de palabras, el apellido de Frieda "Spelling"; el nombre de Alma (se aclara que significa "feraz" (p. 128) pero su fertilidad sólo se circunscribe a un relato que transcribe Zimmer). Brigid O'Fallon aseguraba que la única que merecía llamarse así en honor a la mártir Santa Brígida era su hermana Nora (pp. 167 y 179). Pero se puede ir mucho más lejos: Hemos confirmado que adoptan papeles de héroes y sus nombres son: Hector, David, Helen (la mujer muerta de Zimmer). Además de Xanax, un palíndromo, los protagonistas se retiran a un lugar de Nuevo México que se llama Tierra del Sueño donde hacen cine. Yendo más lejos, nada nos impide suponer que Frieda, pintora, que vive en México y lleva una abnegada vida dedicada a su marido, no sea un nombre que incite a pensar en Frida Kalho.

32 Nada menos que tres películas se nos cuentan: El utilero, Don nadie, La vida íntima de Martin Frost. El recurso de pequeñas novelas dentro de la novela es muy quijotesco y Auster ha reconocido en alguna entrevista su amor por la gran novela cervantina.
} 
rompe una pierna por tres sitios y se fractura varias costillas ${ }^{33}$. Y cuando la palabra se sacraliza porque constituye un instrumento del destino, también los silencios se recargan de valores misteriosos y de significados trascendentes: Hector y Frieda se hacen rodear de "gente menuda que no habla". Alma se enfada por la terquedad de Frieda y asegura "estoy tan cabreada que le daría un puñetazo en la boca"34, algo que no es casual porque como Zimmer observa más adelante, "de ahí es de donde salen las palabras" 35 . En este sentido, el mismo Zimmer deja una puerta entreabierta al final del libro puesto que analiza los silencios de Alma ("he meditado muchos años sobre su silencio" 36 ) como la negación a revelar un secreto: el lugar donde escondió copias de las últimas películas de Hector Spelling.

Por otra parte, Hector Mann deja de actuar cuando aparece la palabra en el cine, él no puede hablar a través del cine y cuando lo hace debe destruir su obra, guardar silencio. Nora O'Fallon le enseña a hablar de nuevo, como si de un salvaje se tratara ${ }^{37}$. Porque guardar silencio es morir. Zimmer había publicado "precisamente" un libro La ruta de Abisinia sobre autores que en un momento de sus vidas cesaron de escribir, "una meditación sobre el silencio: Rimbaud, Dashiel Hammett, Laura Riding, J. D. Salinger..." ${ }^{38}$. Pero es el mismo Zimmer quien no cree en las palabras porque sólo admite la existencia de Hector Mann cuando viene en persona Alma a confirmárselo. Y después parece que lo único que le preocupa es cómo Hector Mann traicionó su palabra de no volver a hacer cine. Alma no llama a David, no establece el puente de las palabras porque quiere morir y sabe que si habla con él tal vez desista de su empeño. Hector Mann había huido, no habla para el público, está muerto. Así pues, en esta obra la palabra manifiesta el doble poder de creación (Eros) y de destrucción (Tanatos).

En La vida íntima de Martin Frost, Claire cobra existencia cuando Martin quema parte de la obra que había escrito inspirado por ella. Destruir palabras, obras, para dar vida. Hector Mann escribe un diario que se nos dice que coincide con su biografía, aunque no sabemos si debemos fiarnos. Frieda quema el libro de Alma y ambas mueren a causa de esas palabras quemadas. "Todo estaba en su libro" afirma Alma, pero ese libro queda reducido a cenizas, como las películas. ¿Es tal vez el fuego purificador? Hector Mann muere, pero sobrevive ${ }^{39}$ porque el libro de Alma se oraliza cuando se lo cuenta a Zimmer, el único que finalmente nos lo narra a nosotros, el único acreditado para "hablar" al lector, para sostener todo ese mundo con las palabras, sin datos, sin otros testigos, sin diarios, sin películas. Sólo nos queda la palabra de los muertos.

\footnotetext{
33 Ibíd., p. 115.

34 Ibíd., p. 299.

35 Ibíd., p. 308.

36 Ibíd., pp. 337-338.

37 Vid. op. cit., p. 179.

38 Op. cit., p. 22.

39 “Tú escribes tu libro (...) pero al mismo tiempo Hector va a sobrevivir gracias a ti. No por sus películas (ibíd., p. 233).
} 
David Zimmer traduce la obra de Chateaubriand: Mémoires d'otre-tombe 40 . Pero David Zimmer tampoco estaba vivo ${ }^{41}$ y a Hector Mann todo el mundo, hasta él en cierto sentido, lo creía muerto ${ }^{42}$. Por tanto, un muerto $\left(Z i m m e r{ }^{43}\right.$ ) habla de otros dos muertos (Mann y Chateabriand). Este es el triángulo sobre el que se asienta la novela. Los tres sostenidos por el vértice de la palabra: alguien tiene que contar esto. Aunque tal vez lo fundamental en el libro es lo que no se cuenta, las conclusiones que debemos sacar los lectores porque somos nosotros quienes nos descubrimos buscando otras coincidencias dentro y fuera del libro. Quizás ese es su mejor logro. ${ }^{44}$

Los filósofos buscan la verdad a través del lenguaje. Y lo único que tenemos de las existencias pasadas son las palabras. Constituye esta obra un buen alegato del deconstruccionismo de Derrida aunque no pretenda ser un libro total o un libro filosófico. Su naturaleza es la fabulación, su entraña es el lenguaje y su envoltorio son las palabras. Nada es verdad: "No (me) queda casi nada: ni la cosa, ni su existencia, ni la mía, ni el puro objeto ni el puro sujeto, ningún interés de ninguna naturaleza por nada" 45 .

Paul Auster recoge algunos de los tópicos clásicos y medievales para reescribirlos y actualizarlos en un mundo de héroes modernos que se debaten entre el nihilismo y la palabra sagrada del arte efímero, frente a un destino adverso que los zarandea como peleles en la comedia de la vida. Ante ellos la insustancialidad de la existencia, la inercia de una vida llena de nadas en el interregno de los hechos cruciales, en los paréntesis entre una y otra vida:

Volví a casa. nada ocurrió en el vuelo a Boston. Encontramos ciertas turbulencias en el Medio Oeste, comí un poco de pollo y bebí un vaso de vino, miré por la ventanilla; pero no pasó nada. Nubes blancas, un ala plateada, el cielo azul. Nada. ${ }^{46}$

Más allá del deconstruccionismo y del posmodernimo, finalmente este libro es una fabulación, un cuento. Hay en él héroes (Hector Man, David Zimmer), princesas (Frieda para Hector, Alma para David, Claire para Martin) a las que rescatar (Hector lo consigue, David fracasa dos veces: con Helen y con

\footnotetext{
${ }^{40}$ Por cierto, la traducción libre que realiza Zimmer del título también es significativa: Memorias de un muerto, y no de ultratumba que sería su sentido literal. Es más, Zimmer recoge que el deseo inicial de Chateaubriand era que este libro no se publicara hasta cincuenta años después de su muerte $\mathrm{y}$, aunque su anhelo se vio frustrado por necesidades económicas no deja de estar escrito "literalmente con la voz de un muerto" (ibíd., pp. 71-72).

41 “...pero verdaderamente yo ya no era nadie, no estaba realmente vivo. Sólo era alguien que fingía estar vivo, un muerto que pasaba el tiempo traduciendo el libro de un muerto" (op. cit., pp. 113-114).

42 Esta es la frase inicial del Libro de las ilusiones, pero en la p. 73 vuelve a insistir: "Nadie ha estado con Hector Mann desde 1929. Está muerto. Tan muerto como Chateaubriand o Madame Récamier. Tanto como ese Dexter como se llame."

43 "Cuando se publique este libro, querido lector, podrá tener la seguridad de que su autor lleva mucho tiempo muerto" (ibíd., p. 335).

${ }^{44}$ Por ejemplo la insistencia en cifras determinadas a lo largo de la novela nos hace pensar en significados cabalísticos o simplemente simbólicos.

45 Jacques Derrida, citado por Julio Cortázar en "Diario para un cuento", Cuentos Completos II, Madrid, Alfaguara, 1994, p. 490.

${ }^{46}$ Ibíd., p. 330.
} 
Alma, Martin también lo logra), pero también aparecen monstruos a los que vencer (la culpa, el dolor, la soledad, el tiempo, la soberbia del artista, en definitiva, el fatum) y una bruja mala (Frieda) asistida por pequeños, traviesos y silenciosos duendes ("gente menuda que no habla") hay, en fin, varitas mágicas en manos del destino (revólveres que disparan o se abstienen de disparar) y un ángel ("un ser en llamas"47). Una metáfora más de la realidad, una analogía tan verdadera y tan falsa como cualquiera de las películas que se cuentan dentro del libro, tan verosímil y tan increíble como cualquier leyenda o mito de la antigüedad, palabras de muertos que se oyen a través de los siglos, botellas con mensajes arrojadas al mar del tiempo. Entonces, ¿qué nos queda? Nomina nuda tenemus, ya lo decía Umberto Eco, o en versión de Shakespeare: "the rest is silence"

47 Ibíd., p. 305. 